\title{
Interactions between protein and vegetable oils in the maternal diet determine the programming of the insulin axis in the rat
}

\author{
Christopher A. Maloney, Christina Lilley, Alicja Czopek, Susan M. Hay and William D. Rees* \\ Rowett Research Institute, Greenburn Road, Bucksburn, Aberdeen, AB21 9SB, UK
}

(Received 20 July 2006 - Revised 20 November 2006 - Accepted 20 November 2006)

\begin{abstract}
The available evidence suggests that metabolic control mechanisms are programmed early in life. Previous studies of pregnant rats fed low-protein diets have suggested that the vegetable oils used in the experimental diets influence the outcome. The present study investigated the offspring of female rats fed semi-synthetic diets containing either 180 or $90 \mathrm{~g}$ casein $/ \mathrm{kg}$ with $70 \mathrm{~g} / \mathrm{kg}(\mathrm{w} / \mathrm{w})$ of either corn oil or soya oil during gestation. During lactation, the dams received stock diet, and the offspring were subsequently weaned onto the stock diet. The offspring of dams fed the low-protein diets were smaller at birth. At 25 weeks of age, the offspring were subjected to an oral glucose tolerance test. In the offspring of dams fed the diet containing soya oil, the area under the insulin curve was affected by the protein content of the maternal diet. There was no effect of protein on the area under the insulin curve in the offspring of dams fed the diet prepared with corn oil. There were no differences in plasma glucose concentrations. The levels of mRNA for acetyl-CoA carboxylase-1 in the livers of female offspring were affected by the protein and oil content of the maternal diet. The level of carnitine palmitoyl transferase mRNA was affected by the protein content of the maternal diet. The present study suggests that PUFA in the maternal diet can interact with protein metabolism to influence the development of the offspring. This may involve the higher content of $\alpha$-linolenic acid in soya oil compared with corn oil.
\end{abstract}

Fetal programming: Low protein diet: Insulin resistance: Glucose tolerance: Acetyl-CoA carboxylase: Carnitine palmitoyl transferase: Oil protein interactions

PUFA are essential for early growth and development (Uauy et al. 2000). The fatty acid composition of the human diet has changed markedly over the past 100 years owing to an increase in the use of vegetable oils, including corn oil, and soyabeans (Simopoulos, 1999). The ratio of $n-3$ to $n-6$ PUFA in the diet of pregnant rats has been shown to be a factor that modulates metabolic programming during fetal development, leading to long-lasting effects on the offspring (Korotkova et al. 2002, 2004). Critically, the levels of PUFA and saturated fatty acids in the maternal diet determine glucose-stimulated insulin release in the offspring (Siemelink et al. 2002). The lipid component of the diet may also be important in other models of metabolic programming such as modest protein restriction. The offspring of dams fed a low-protein diet that was prepared with soya oil have a hypoinsulinaemic response to a glucose challenge (Rees et al. 2006b). When the same experiment was performed using diets prepared with corn oil and different carbohydrate components, however, the protein content of the maternal diet had no effect on either the peak insulin release or the total area under the curve (Rees et al. $2006 a$ ). These observations suggested that the type of vegetable oil used in the diet may have been an important factor.

In adult rats, an increase in the linolenic acid $(n-3)$ content of the diet improves insulin sensitivity and glucose tolerance by changing the insulin response in the target tissues (Storlien et al. 1997; Ghafoorunissa et al. 2005; Nettleton \& Katz, 2005). The PUFA composition of the diet modifies the ability of insulin to regulate hepatic genes that code for the enzymes controlling the metabolism of lipids: acetyl-CoA carboxylase (ACC-1) and carnitine palmitoyl transferase (L-CPT-1) (Iritani et al. 1995). The expression of these enzymes is also programmed by protein deficiency during pregnancy (Maloney et al. 2003). The first aim of the present study was to evaluate the interactions between modest protein restriction and the fatty acid composition of the diet. The second aim was to investigate whether the PUFA composition of the maternal diet modulated the effects of protein restriction during gestation on the programming of the enzymes that control fat partitioning in the offspring. This was achieved through the use of a two-way factorial design in which pregnant dams were fed diets with high or low protein contents prepared with either corn or soya oil.

\section{Methods \\ Experimental diets}

The composition of the semi-synthetic casein-based diets were based on those described previously by Langley-Evans et al. (1996). The fat content was reduced to $70 \mathrm{~g} / \mathrm{kg}$ and

\footnotetext{
Abbreviations: ACC, acetyl-CoA carboxylase; L-CPT-1, carnitine palmitoyl transferase; REML, residual maximum likelihood

* Corresponding author: Dr William D. Rees, fax +44 (0) 1224 716622, email wdr@ rri.sari.ac.uk
} 
the methionine to $2 \mathrm{~g} / \mathrm{kg}$ in the diet containing $18 \%$ protein, and $1 \mathrm{~g} / \mathrm{kg}$ in the diet containing $9 \%$ protein. The full composition of the diets is shown in Table 1 . The vitamin and mineral mixes conformed to the American Institute of Nutrition AIN-93 G formulation (ICN Biomedicals, Basingstoke, Hampshire, UK). Choline chloride and methionine were from Sigma (Poole, Dorset, UK), whereas the other ingredients were from Special Diet Services (Witham, Essex, UK). The fatty acid composition of the corn and soya oils corresponded to the analysis given by the manufacturers.

\section{Animals}

All experiments were performed using rats of the Rowett Hooded Lister strain bred in the Institute's own colony. All experimental procedures were approved by the Ethical Review Committee of the Rowett Research Institute and conducted in accordance with the UK Animals (Scientific Procedures) Act, 1986.

Female rats aged 8 weeks old with an average body weight of approximately $220 \mathrm{~g}$ were assigned to four groups (ten per group), each group then being fed one of the four experimental diets ad libitum. There were no significant differences between the average weight of animals in each of the four groups at the start of the experiment. Two weeks later, when the average body weight was approximately $250 \mathrm{~g}$, the animals were mated with males of the same strain. Mating was confirmed by detection of a vaginal plug. The female rats were maintained on the same diets throughout pregnancy. To determine the haematocrit and biochemical parameters, blood samples were taken from the dams on day 11 of gestation by venesection at the tip of the tail. Blood was collected in a heparinised tube and centrifuged at $12000 \mathrm{~g}$ for $5 \mathrm{~min}$ to remove the blood cells; the plasma was stored at $-80^{\circ} \mathrm{C}$ for subsequent analysis. Two animals were not pregnant: one in the $18 \%$ protein and soya oil group and one in the $9 \%$ protein and corn oil group. Litters of fewer than six pups (three litters) were excluded, and a further five litters were lost after birth.

Pups were delivered naturally, and on postnatal day 1 the litters were culled to eight pups/dam, with four males and four females where possible. Immediately after parturition, the dams were fed stock laboratory chow (CRM (P) breeder and grower diet 801722; Special Diet Services) ad libitum until weaning was complete. The offspring were weaned onto the same stock diet, and this was fed ad libitum for the remainder of the experiment. The offspring were grouphoused and weighed twice weekly to monitor growth. Where possible, three males and three females were killed at 6 weeks of age and the remaining animals at 25 weeks of age. The animals were rapidly dissected and tissues weighed, flash-frozen in liquid $\mathrm{N}$ and stored at $-80^{\circ} \mathrm{C}$ until subsequent analysis.

\section{Plasma and haematological measurements}

Amino acid analysis was performed on an aliquot of maternal plasma (sample from day 11 of gestation) as previously described (Rees et al. 1999). Fatty acids were extracted from plasma by chloroform-methanol extraction and transesterified in methanolic $\mathrm{HCl}$. The component fatty acid 
methyl esters were extracted and dried prior to being separated and analysed by GC and MS (Christie, 1990).

\section{Glucose tolerance tests}

Glucose tolerance tests were performed on the offspring at 25 weeks of age. Briefly, animals were fasted overnight, and a baseline blood sample of approximately $150 \mu \mathrm{l}$ was taken from the tail vein. A single dose $(200 \mathrm{mg} / 100 \mathrm{~g}$ body weight) of a $30 \% \mathrm{w} / \mathrm{v}$ D-glucose solution was then administered by gavage. Over the following $90 \mathrm{~min}$, six blood samples of approximately $150 \mu \mathrm{l}$ were collected in a heparin-treated tube following venesection of the tail vein. Red blood cells were removed by centrifugation, and plasma glucose was estimated using glucose oxidase, peroxidase and 4-amino-antipyrine (Maloney et al. 2003). Plasma insulin was measured by ELISA following the manufacturer's instructions (Mercodia, Uppsala, Sweden).

\section{Semi-quantitative $R T-P C R$}

Total RNA was extracted from liver using the Trizol reagent (Sigma). Samples of $50 \mathrm{ng}$ were reverse-transcribed using the TaqMan Reverse Transcription Reagents Kit (Applied Biosystems, Warrington, Cheshire, UK) primed with random hexamers. The sequences of the primers used for the PCR of liver ACC-1 and liver L-CPT-1 cDNAs are given in Table 2. The levels of cDNA relative to the $18 \mathrm{~S}$ ribosomal RNA were measured using the SYBR Green real-time PCR kit (Applied Biosystems), following the reactions for 40 cycles of PCR using an ABI Prism 7700 Sequence Detection System (Applied Biosystems) to determine the threshold cycle as previously described (Maloney et al. 2005). Ranges of primer concentration were tested to determine the optimum PCR yield, and the presence of a single PCR product was verified by estimating the melting curve for each sample at the end of the reaction. PCR products were cloned and sequenced to confirm their identity. Relative target quantity was calculated from a standard curve of pooled liver cDNA and the results expressed as the ratio of the product relative to the product from the 18S rRNA for each RT sample. Each RT reaction was carried out in triplicate.

\section{Statistics}

All data are presented as means and their standard errors. Data were analysed in Genstat 8, version 8.1 (VSN International Ltd, Hemel Hempstead, Hertfordshire, UK). Body weight and food intake (Figs. 1 and 2) were analysed as repeated measures using residual maximum likelihood (REML), with animal as a random effect and fixed effects for protein, oil, day of gestation and their interactions. An autoregressive correlation structure of order 1 was assumed for observations within animal across time. The data in the tables were analysed for each sex separately. Differences between groups were compared using two-way ANOVA using maternal dietary protein content and oil type as factors, or by REML, with fixed effects for sex, oil and protein, and their interactions. Area under the curve for glucose and insulin (see Fig. 4) was calculated using the PK2 add-in for Microsoft Excel (Usansky \& Desai, Department of Pharmacokinetics and Drug Metabolism, Allergan, Irvine, CA, USA). This was then analysed with REML, with fixed effects for sex, oil and protein, and their interactions.

\section{Results}

\section{Maternal characteristics}

During the 2-week period prior to mating, there was no significant difference in the food intake between the different groups, the average consumption being 20.3 (SE 0.6) $\mathrm{g} / \mathrm{d}$. The dams grew similarly on all four diets, and after 2 weeks of feeding there were no significant differences in body weight between the groups. At mating, the average body weight was 253.2 (SE 2.4) g. The average body weights of the dams in the four different diet groups were not significantly different before day 19 of gestation (day -3 before birth). However, as Fig. 1 shows, the average body weights of dams consuming the low-protein diets were significantly lower than those fed the high-protein diets during the last 3 $\mathrm{d}$ of gestation $(P<0.001)$.

Food intake was also affected by the protein content of the diet $(P<0 \cdot 003)$. The dams fed the low-protein diets consumed approximately $20 \%$ less food (see Fig. 2) and gained approximately $9 \mathrm{~g}$ less body weight between day 19 and birth. The type of dietary oil did not directly affect food intake, but the animals fed the $18 \%$ protein diet containing soya oil consumed more than the animals in the other three groups on the second last day before birth (protein, $P=0.003$; protein by oil interaction, $P=0.023$ ). After birth, the dams fed the low-protein diets were smaller than those fed the high-protein $\operatorname{diet}(P=0 \cdot 003)$. Once the animals were returned to stock diets, the groups were similar in body weight by postnatal day 4 (see Fig. 1).

Maternal circulation. The maternal haematocrit on day 11 of gestation was lower for animals in the two low-protein groups compared with the high-protein groups $(40.4 \% v$. $41.9 \%$ packed cell volume; $P<0 \cdot 001)$. Table 3 shows the concentrations of free amino acids in the maternal plasma on day 11 of gestation. The concentrations of alanine, aspartic acid, glutamine and glycine were all increased in the plasma of dams fed the low-protein diets. At the same time, there were decreases in the concentrations of histidine, isoleucine,

Table 2. Primer sequences used in real time RT-PCR

\begin{tabular}{|c|c|c|c|}
\hline Gene & Forward primer & Reverse primer & Accession number \\
\hline 18S rRNA & CGGCTACCACATCCAAGGAA & GCTGGAATTACCGCGGCT & V01270 \\
\hline Acetyl-CoA carboxylase-1 & CAACGCCTTCACACCACCTT & AGCCCATTACTTCATCAAAGATCCT & NM_022193.1 \\
\hline Carnitine palmitoyl transferase- 1 & CGGTTCAAGAATGGCATCATC & TCACACCCACCACCACGATA & L07736 \\
\hline
\end{tabular}




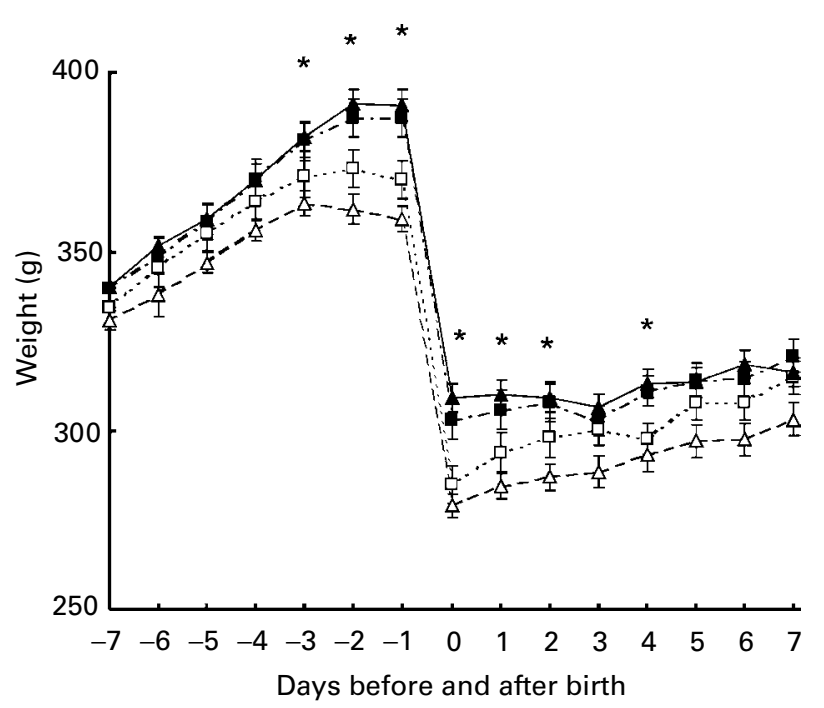

Fig. 1. Live weights of rat dams during the last week of gestation and the first week after birth. Diet groups are as follows: $18 \%$ protein + corn oil $(\boldsymbol{\square})$; $18 \%$ protein + soya oil $(\Lambda) ; 9 \%$ protein + corn oil $(\square) ; 9 \%$ protein + soya oil $(\Delta)$. Daily data points were estimated from the growth curves and were then aligned according to the day of birth. Pre- and postpartum data were analysed separately by residual maximum likelihood (REML). Values are means and their standard errors from the REML analysis. Before birth, REML analysis showed significant effects for day $(P<0.001)$ and protein $(P=0.008)$, and a protein by day interaction $(P<0.001)$. After birth, there were significant effects for day $(P<0.001)$ and protein $(P=0.008)$, and a protein by day interaction $(P=0.007)$. All other effects were not significant $(P>0.1)$. ${ }^{*}$ Significant difference for effect of protein level on growth when tested one day at a time $(P<0.05)$.

leucine, methionine, phenylalanine, serine, threonine, tryptophan, tyrosine and valine.

The type of oil used in the diet had no effect on the amino acid profile. The day 11 maternal plasma fatty acid profiles were similar for each of the groups except that $\alpha$-linolenic

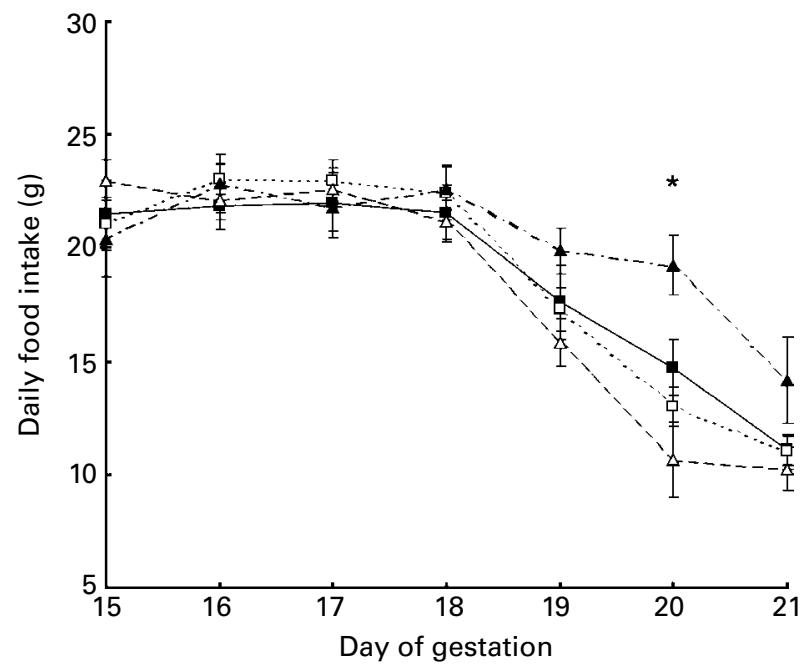

Fig. 2. Maternal food intake during the last week of gestation. Diet groups are as follows: $18 \%$ protein + corn oil $(\boldsymbol{\square}) ; 18 \%$ protein + soya oil $(\boldsymbol{\Lambda}) ; 9 \%$ protein + corn oil $(\square) ; 9 \%$ protein + soya oil $(\Delta)$. Food intakes were recorded daily and aligned according to the day of birth. Data were analysed by residual maximum likelihood, and values are means and their standard errors from this analysis. *Significant difference for protein level $(P<0.05)$. acid (18:3n-3) was detected only in the plasma of the dams fed the soya diet (data not shown). This difference in maternal plasma $\alpha$-linolenic acid reflected the respective fatty acid composition of soya and corn oil.

\section{Offspring characteristics}

All animals gave birth to viable litters, with numbers comparable to those found in previous experiments using the same strain of rat. The ratio of male to female offspring was similar in all four groups. Table 4 shows that there were no differences in mean litter size. Before the pups were culled on day 1, the offspring (combined male and female) of dams fed the low-protein diets had a lower body weight $(P=0.024)$ than those of dams fed the high-protein diet. The type of oil used in the maternal diet had no effect on body weight on day 1 . There was no overall effect of the maternal diet on the average weaning weight of the male and female offspring (Table 4).

The post-weaning food intake was determined at 22 weeks of age and was not found to be different between the groups (data not shown). The growth of the male offspring was not influenced by the maternal diet during gestation, and at 25 weeks of age the average body weights of animals in the four groups were no different (Table 4). There was also no difference in the incremental area under the growth curves of the male offspring from weaning to 24 weeks of age. The body weight of the female offspring is shown in Table 4. There was a trend $(P=0.075)$ for the average body weight of the offspring of dams fed diets containing soya oil to be lower at 25 weeks of age than those of dams fed corn oil. This was confirmed by comparing the incremental area under the growth curves, which was significantly different for female offspring of dams fed diets containing soya oil in comparison with those fed corn oil $(P=0 \cdot 022)$. Analysis of the combined data for males and females by REML showed a significant effect of $\operatorname{sex}(P<0.001)$ and protein $(P=0 \cdot 046)$, suggesting that the offspring of dams fed the low-protein diet were approximately $5 \%$ smaller than those of dams fed the high-protein diet.

There were no differences in organ weight expressed as a percentage of body weight in either the male or female offspring at 6 weeks of age (data not shown). In the males at 25 weeks of age, there were again no differences in organ weight between groups except for the weight of the heart, which was lower $(P=0.03)$ in the offspring of dams fed the soya oil diets (Table 5). In contrast, for the female offspring there were differences due to the type of oil used in the maternal diet in the absolute weights of the kidney $(P=0.05)$ and plantaris muscle $(P=0 \cdot 02)$. Analysis of the combined data by REML showed a similar result. The heart was reduced by $6 \%(P=0.007)$, the weight of the plantaris by $8 \%(P=0.014)$ and that of the kidneys by $5 \%$ $(P=0.035)$ in the offspring of dams fed the soya oil diet. There was no effect of protein, and there were no interactions.

Glucose tolerance and insulin measurements. The prenatal diet did not induce differences in either the fasting plasma glucose or insulin concentration at 25 weeks of age Baseline insulin concentrations were 20.4 (SE 1.5) $\mu \mathrm{U} / \mathrm{ml}$ ( $n$ 25) for the males and 13.5 (SE 1.7) $\mu \mathrm{U} / \mathrm{ml}(n$ 25) for the 
Table 3. Maternal plasma amino acid profile at day 11 of gestation

(Mean values with their standard errors for all dams in the study with litters of more than five pups; nmol/g plasma)

\begin{tabular}{|c|c|c|c|c|c|c|c|c|c|c|c|}
\hline \multirow{2}{*}{$\begin{array}{l}\text { Diet ... } \\
\text { Amino acid }\end{array}$} & \multicolumn{2}{|c|}{$18 \mathrm{C}(n 8)$} & \multicolumn{2}{|c|}{$18 S(n 5)$} & \multicolumn{2}{|c|}{$9 \mathrm{C}(n 8)$} & \multicolumn{2}{|c|}{$9 \mathrm{~S}(n 9)$} & \multicolumn{3}{|c|}{ Two-way ANOVA $P$ value } \\
\hline & Mean & SE & Mean & SE & Mean & SE & Mean & SE & Protein & Oil & Interaction \\
\hline ALA & 387.3 & $26 \cdot 2$ & 381.9 & $51 \cdot 7$ & $468 \cdot 7$ & $22 \cdot 7$ & 432.5 & $32 \cdot 0$ & 0.05 & 0.5 & 0.6 \\
\hline ARG & 113.9 & 7.5 & 114.2 & 9.0 & $100 \cdot 5$ & 5.9 & $120 \cdot 9$ & $20 \cdot 9$ & 0.8 & 0.4 & 0.5 \\
\hline ASN & 73.5 & $4 \cdot 3$ & $75 \cdot 3$ & 7.9 & 69.4 & $2 \cdot 7$ & 67.6 & $3 \cdot 1$ & 0.2 & 0.9 & 0.7 \\
\hline ASP & 6.9 & 0.9 & $6 \cdot 6$ & 0.5 & 9.4 & $1 \cdot 0$ & $10 \cdot 5$ & $1 \cdot 2$ & 0.006 & 0.6 & 0.5 \\
\hline GLN & 574.8 & $12 \cdot 6$ & 583.7 & $16 \cdot 0$ & 631.0 & $14 \cdot 2$ & $675 \cdot 8$ & 14.9 & 0.001 & 0.06 & 0.2 \\
\hline GLU & 58.9 & 8.5 & 57.0 & 8.8 & $75 \cdot 8$ & $10 \cdot 1$ & 74.2 & $12 \cdot 9$ & 0.1 & 0.9 & 1.0 \\
\hline GLY & 132.9 & $8 \cdot 3$ & $140 \cdot 2$ & 19.8 & $172 \cdot 7$ & $6 \cdot 4$ & $169 \cdot 9$ & $10 \cdot 4$ & 0.003 & 0.9 & 0.6 \\
\hline HIS & 33.7 & 2.5 & 38.0 & 4.4 & 28.6 & $3 \cdot 0$ & $25 \cdot 7$ & 1.4 & 0.005 & 1.0 & 0.2 \\
\hline ILE & 114.9 & $6 \cdot 1$ & 112.9 & $15 \cdot 2$ & 79.4 & $4 \cdot 7$ & 82.9 & 4.8 & 0.001 & 0.9 & 0.7 \\
\hline LEU & $177 \cdot 2$ & $10 \cdot 5$ & $172 \cdot 5$ & 24.6 & $119 \cdot 1$ & $6 \cdot 7$ & $126 \cdot 6$ & 7.4 & 0.001 & 0.8 & 0.6 \\
\hline LYS & 774.8 & $55 \cdot 6$ & $763 \cdot 1$ & $61 \cdot 7$ & $745 \cdot 1$ & $58 \cdot 9$ & 737.8 & $28 \cdot 8$ & 0.6 & 0.9 & 1.0 \\
\hline MET & $132 \cdot 2$ & $10 \cdot 2$ & $111 \cdot 1$ & 11.3 & 97.5 & 5.5 & 87.5 & 5.9 & 0.001 & 0.08 & 0.5 \\
\hline PHE & 76.5 & $2 \cdot 7$ & $75 \cdot 7$ & 4.7 & 63.6 & $3 \cdot 2$ & $65 \cdot 8$ & $2 \cdot 7$ & 0.001 & 0.8 & 0.7 \\
\hline PRO & $355 \cdot 2$ & 33.2 & $311 \cdot 0$ & $45 \cdot 9$ & 331.9 & $20 \cdot 2$ & 282.6 & $30 \cdot 1$ & 0.3 & 0.2 & 0.9 \\
\hline SER & 285.9 & $13 \cdot 1$ & 283.0 & 21.9 & 239.6 & $14 \cdot 1$ & 228.3 & $11 \cdot 2$ & 0.001 & 0.6 & 0.8 \\
\hline TAU & 204.5 & $13 \cdot 4$ & 229.9 & 30.6 & $182 \cdot 7$ & $22 \cdot 6$ & $196 \cdot 0$ & $16 \cdot 5$ & 0.2 & 0.4 & 0.8 \\
\hline THR & $667 \cdot 0$ & $52 \cdot 6$ & $717 \cdot 7$ & 89.8 & $315 \cdot 3$ & $51 \cdot 2$ & 308.5 & $32 \cdot 2$ & 0.001 & 0.7 & 0.6 \\
\hline TRP & $127 \cdot 2$ & $5 \cdot 1$ & $128 \cdot 1$ & 7.4 & 101.9 & $6 \cdot 0$ & 102.5 & $3 \cdot 2$ & 0.001 & 0.9 & 1.0 \\
\hline TYR & $105 \cdot 7$ & $5 \cdot 1$ & 101.5 & $7 \cdot 3$ & 85.9 & $5 \cdot 3$ & 81.9 & 3.7 & 0.001 & 0.4 & 1.0 \\
\hline VAL & 274.9 & $15 \cdot 9$ & 264.3 & 35.2 & 187.4 & 17.4 & $182 \cdot 3$ & 9.5 & 0.001 & 0.7 & 0.9 \\
\hline
\end{tabular}

18C, $18 \%$ protein-corn oil; $18 \mathrm{~S}, 18 \%$ protein-soya oil; $9 \mathrm{C}, 9 \%$ protein-corn oil; $9 \mathrm{~S}, 9 \%$ protein-soya oil.

Table 4. Effect of dietary protein and lipid composition on litter size and weight

(Mean values with their standard errors for all dams in the study with litters of more than five pups)

\begin{tabular}{|c|c|c|c|c|c|c|c|c|c|c|c|}
\hline \multirow[t]{2}{*}{ Diet . } & \multicolumn{2}{|c|}{$18 C(n 8)$} & \multicolumn{2}{|c|}{$18 S(n 5)$} & \multicolumn{2}{|c|}{$9 \mathrm{C}(n 8)$} & \multicolumn{2}{|c|}{$9 S(n 9)$} & \multicolumn{3}{|c|}{ Two-way ANOVA $P$ value } \\
\hline & Mean & SE & Mean & SE & Mean & SE & Mean & SE & Protein & Oil & Interaction \\
\hline Average litter size & $12 \cdot 1$ & 1.3 & 11.4 & 1.6 & $13 \cdot 0$ & 1.0 & $14 \cdot 0$ & 0.6 & 0.1 & 0.6 & 0.4 \\
\hline Average birth weight of pups in litter (g) & $6 \cdot 2$ & 0.2 & $6 \cdot 0$ & 0.3 & 5.5 & 0.2 & 5.4 & 0.3 & 0.024 & 0.6 & 1.0 \\
\hline Male weaning body weight $(\mathrm{g})$ & $37 \cdot 4$ & 0.6 & $40 \cdot 0$ & 1.7 & $40 \cdot 3$ & 1.2 & $37 \cdot 8$ & 1.4 & 0.6 & 0.7 & 0.067 \\
\hline Female weaning body weight (g) & $37 \cdot 6$ & 0.7 & $37 \cdot 9$ & $1 \cdot 1$ & $40 \cdot 0$ & 0.7 & $37 \cdot 0$ & 1.43 & 0.6 & 0.1 & 0.1 \\
\hline Male body weight 25 weeks of age $(\mathrm{g}) \dagger$ & $503 \cdot 2$ & 14.4 & $495 \cdot 7$ & 20.5 & $469 \cdot 1$ & $21 \cdot 2$ & $480 \cdot 8$ & 9.9 & $0 \cdot 1$ & 0.9 & 0.6 \\
\hline Female body weight 25 weeks of age $(\mathrm{g}) \dagger$ & $288 \cdot 8$ & 5.5 & $278 \cdot 6$ & $5 \cdot 3$ & $282 \cdot 8$ & $6 \cdot 2$ & 269.5 & $7 \cdot 7$ & 0.2 & 0.075 & 0.8 \\
\hline
\end{tabular}

$18 \mathrm{C}, 18 \%$ protein-corn oil; $18 \mathrm{~S}, 18 \%$ protein-soya oil; $9 \mathrm{C}, 9 \%$ protein-corn oil; $9 \mathrm{~S}, 9 \%$ protein-soya oil.

† Weights at 25 weeks are from animals that were fasted overnight.

Table 5. Offspring organ weights at 25 weeks in relation to maternal diet during pregnancy

\begin{tabular}{|c|c|c|c|c|c|c|c|c|c|c|c|}
\hline \multirow[t]{2}{*}{ Diet. } & \multicolumn{2}{|c|}{$18 \mathrm{C}(n 8)$} & \multicolumn{2}{|c|}{$18 S(n 5)$} & \multicolumn{2}{|c|}{$9 \mathrm{C}(n 8)$} & \multicolumn{2}{|c|}{$9 S(n 9)$} & \multicolumn{3}{|c|}{ Two-way ANOVA $P$ value } \\
\hline & Mean & SE & Mean & SE & Mean & SE & Mean & SE & Protein & Oil & Interaction \\
\hline \multicolumn{12}{|l|}{ Male offspring } \\
\hline Liver $(\mathrm{g})$ & 14.61 & 0.67 & 14.03 & 0.35 & 14.50 & 0.41 & 13.86 & 0.60 & 0.8 & 0.3 & 1.0 \\
\hline Heart (g) & 1.34 & 0.046 & 1.26 & 0.042 & 1.32 & 0.023 & 1.23 & 0.033 & 0.5 & 0.03 & 0.9 \\
\hline Average, kidney (g) & 1.66 & 0.042 & 1.65 & 0.086 & $1 \cdot 70$ & 0.044 & 1.58 & 0.070 & 0.9 & 0.2 & 0.3 \\
\hline Epididymal fat $(\mathrm{g})$ & 11.82 & 0.41 & 11.06 & 0.68 & 11.43 & 0.75 & $10 \cdot 68$ & 0.63 & 0.5 & 0.2 & 1.0 \\
\hline Soleus $(\mathrm{g})$ & 0.429 & 0.016 & 0.437 & 0.031 & 0.391 & 0.035 & 0.418 & 0.016 & 0.3 & 0.6 & 0.7 \\
\hline Plantaris $(\mathrm{g})$ & 0.748 & 0.021 & 0.704 & 0.061 & 0.727 & 0.031 & 0.698 & 0.033 & 0.7 & 0.3 & 0.8 \\
\hline \multicolumn{12}{|l|}{ Female offspring } \\
\hline Liver $(\mathrm{g})$ & 8.34 & 0.334 & $7 \cdot 87$ & 0.272 & $7 \cdot 96$ & 0.233 & 7.42 & 0.222 & 0.2 & 0.06 & 0.9 \\
\hline Heart (g) & 0.93 & 0.021 & 0.88 & 0.022 & 0.91 & 0.020 & 0.89 & 0.019 & $0 . \overline{8}$ & 0.2 & 0.4 \\
\hline Average, kidney (g) & 1.00 & 0.038 & 0.95 & 0.019 & 0.98 & 0.027 & 0.91 & 0.026 & 0.4 & 0.05 & $0 \cdot 8$ \\
\hline Ovarian fat $(\mathrm{g})$ & 9.0 & 0.659 & 9.9 & 0.343 & $8 \cdot 8$ & 0.817 & 9.2 & 0.962 & 0.6 & 0.5 & 0.8 \\
\hline Soleus (g) & 0.287 & 0.012 & 0.284 & 0.025 & 0.272 & 0.009 & 0.259 & 0.011 & 0.2 & 0.4 & 0.7 \\
\hline Plantaris $(\mathrm{g})$ & 0.455 & 0.018 & 0.450 & 0.031 & 0.473 & 0.034 & 0.368 & 0.020 & 0.4 & 0.02 & 0.08 \\
\hline
\end{tabular}

One male and one female offspring from each litter were fasted and subjected to a glucose tolerance test before being killed. Data were analysed using two-way ANOVA.

$18 \mathrm{C}, 18 \%$ protein-corn oil; $18 \mathrm{~S}, 18 \%$ protein-soya oil; $9 \mathrm{C}, 9 \%$ protein-corn oil; $9 \mathrm{~S}, 9 \%$ protein-soya oil. 
females. Baseline blood glucose concentrations were $6 \cdot 1$ $(\mathrm{SE} 0 \cdot 1) \mathrm{mM}(n$ 25) for the males and $6.5(\mathrm{SE} 0 \cdot 2) \mathrm{mM}(n$ 25) for the females.

Following the oral glucose load, there was a transient increase in plasma glucose concentration, similar to that previously reported (Rees et al. 2006b). The prenatal dietary treatment produced no significant differences in glucose concentration or in the total incremental area under the curve during the following $90 \mathrm{~min}$ in either male or female offspring. Insulin concentrations at individual time points were not significantly different when comparing the male or female offspring of dams fed high- or low-protein diets containing soya or corn oil (Fig. 3). The total area under the insulin curve was higher in the male than in the female offspring $(P<0 \cdot 001$; Fig. 4). There was a tendency for the difference between males and females to be greater in the offspring of dams fed corn oil than in the offspring of dams fed soya oil $(P=0.050$ for sex by oil interaction).

The protein content of the maternal diet had no effect on the insulin area under the curve when it was combined with corn oil, but the area under the curve was reduced, i.e. insulin release was lower for a given level of glucose stimulation, in the offspring of dams fed the low-protein diet containing soya oil when compared with those fed the high-protein diet with soya oil ( $P=0.046$ for protein by oil interaction). The same pattern was observed for both males and females.

The impact of prenatal diet on gene expression was studied in the female offspring as they had reached their mature body weight by 25 weeks of age (see Discussion). Table 6 shows the levels of mRNA for ACC-1 and L-CPT-1 relative to ribosomal 18S RNA in the livers of female offspring $3 \mathrm{~h}$ after the administration of the glucose dose given as part of the glucose tolerance test. The relative expression of ACC-1 was increased in the livers of the offspring from the dams fed the low-protein diet $(P=0.05$; combined means $18 \%$ casein $=29.9$ and $9 \%$ casein $=36 \cdot 1)$. There was also an interaction between the protein content and fatty acid composition of the maternal diet $(P=0.004$ for oil by protein interaction). In contrast, the protein content of the maternal diet was the only factor that influenced the relative level of the L-CPT-1 mRNA, which was increased in the offspring of dams fed the low-protein diet $(P=0.015$; combined means $18 \%$ casein $=33.5$ and $9 \%$ casein $=45 \cdot 6$ ). Although the statistical analysis of the data suggests that there is no protein by oil interaction influencing L-CPT-1 expression, this may be due to the limited power of the present study; a larger experiment might have shown an interaction.
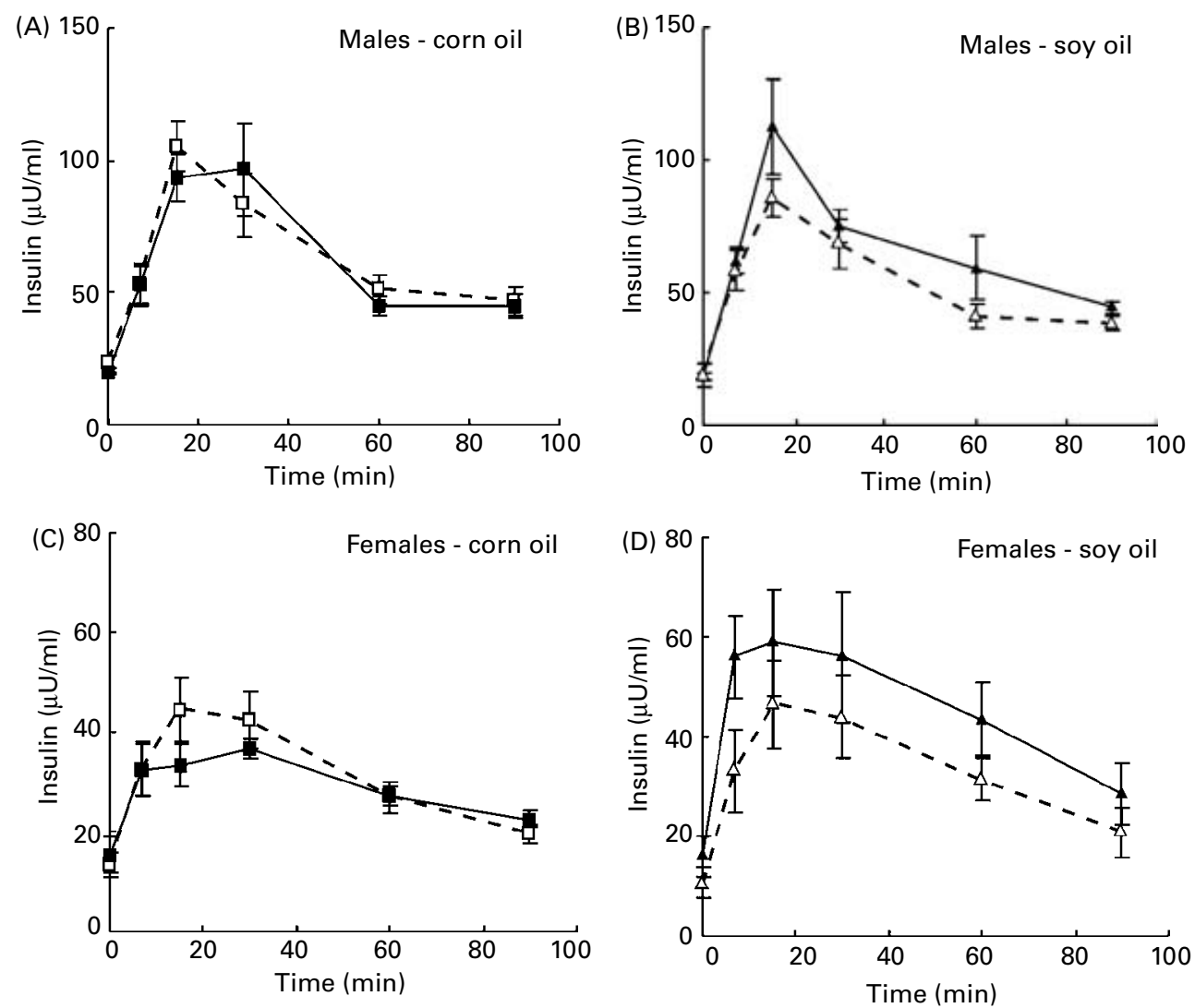

Fig. 3. Changes in plasma insulin after an oral glucose load in 25 -week-old offspring. Diet groups during gestation are as follows: $18 \%$ protein + corn oil $(\mathbf{\square} ; n$ ); $18 \%$ protein + soya oil $(\Lambda ; n 4) ; 9 \%$ protein + corn oil $(\square ; n 7) ; 9 \%$ protein + soya oil $(\Delta ; n 7)$. Values are means and their standard errors. $(\mathrm{A})$ Males - corn oil; (B) males - soya oil; (C) females - corn oil; (D) females - soya oil. 


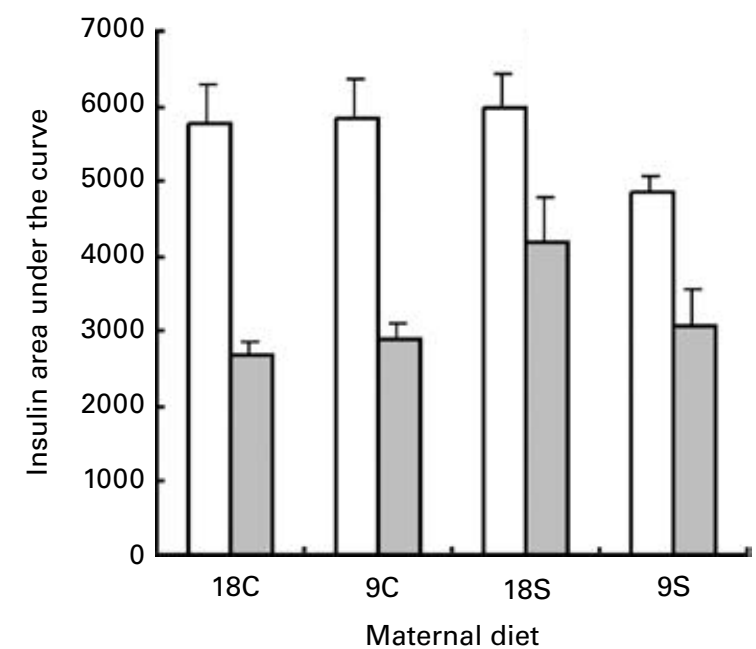

Fig. 4. Area under the plasma insulin concentration curves shown in Fig. 3. Diet groups are as follows: $18 \%$ protein + corn oil $(18 \mathrm{C}) ; 18 \%$ protein + soya oil (18S); $9 \%$ protein + corn oil (9C); $9 \%$ protein + soya oil (9S). Open bars, males (18C $n$ 8, 18S $n$ 4, 9C $n 7$, 9S $n$ 6); filled bars, females (18C $n$ 8, 18S $n$ 4,9C $n 7$, 9S $n$ 7). Values are means and their standard errors. Data were analysed with residual maximum likelihood, with fixed effects for sex, oil and protein, and their interactions. Sex, $P<0.001$; sex $\times$ oil, $P=0.050$; protein $\times$ oil, $P=0.046$.

\section{Discussion}

This study shows that the amount of protein and the type of oil used in the maternal diet interact to produce long-lasting changes in the insulin axis of the offspring. In this respect, the present study replicates our previous observations, which showed that soya-containing diets were associated with reduced insulin release on glucose challenge (Rees et al. $2006 b$ ). The study also replicated previous studies suggesting that a low-protein diet prepared with corn oil does not lead to changes in the insulin axis (Rees et al. 2006a). In these previous studies, however, there were a number of differences in the type and content of lipid and carbohydrate, and also in the balance of amino acids. This made it impossible to separate the effects of the different components. The factorial design of the present study shows that the protein effect on glucose-stimulated insulin release in the offspring is reliant on the type of oil used in the diet.

Corn oil is rich in $n-6$ and relatively poor in $n-3$ fatty acids, whereas soya oil contains a higher proportion of $n-3$ fatty acids. These results suggest that this ratio of $n-3$ to $n-6$ PUFA in the maternal diet modifies the programming of the insulin axis during fetal development. During fetal life, the nutrient supply via the placenta is under homeostatic control from the dam, holding the fetus in the equivalent of a glucose clamp. At birth, there is a transition to a closed system, dependent on feedback from the peripheral tissues (Plagemann, 2005). Eicosanoids derived from PUFA play important roles in insulin release and signalling. In the pancreatic $\beta$-cell, PUFA are substrates for the phospholipases implicated in the glucose-mediated release of insulin, $\beta$-cell proliferation and apoptosis (Ramanadham et al. 2004). Diets rich in $n-3$ PUFA also improve insulin sensitivity in skeletal muscle (D'Alessandro et al. 2002) and adipocytes (Ghafoorunissa et al. 2005). Because eicosanoids derived from $n-3$ or $n-6$ PUFA have differing biological potency, changes in the $n$ $3: n-6$ ratio in the maternal diet may alter signalling and hence sensitivity in fetal tissues. During the transition to a closed system, these changed characteristics of the insulin axis may permanently modify the set points for insulin signalling in the developing fetus. The protein content of the maternal diet is able to regulate the lipid composition of fetal membranes (Marin et al. 1995) and thus alter the production of eicosanoids (Burdge et al. 2002). These interactions may play an important part in the mechanisms underlying the programming of insulin action, which have previously been attributed to protein alone.

The results from the glucose tolerance test also feature an interaction between the oil composition of the diet and the gender of the offspring. It is not uncommon to find differential responses to maternal diet in males and females (Bonnevie-Nielsen, 1980; Korotkova et al. 2005; Zhang et al. 2005; Zambrano et al. 2006). The signalling molecules derived from the eicosanoid family are important mediators of steroid hormone action, including sex steroids and glucocorticoids. These hormones affect male and female fetuses differently, possibly accounting for the gender effects between dietary oil and sex seen in the glucose tolerance test. A sex-dependent effect involving the glucocorticoid axis has previously been demonstrated in rats, as the male offspring of dams fed protein-deficient diets exhibited glucocorticoid-dependent hypertension, unlike the females, in which hypertension was independent of glucocorticoid status (McMullen \& Langley-Evans, 2005). The growth characteristics of the two sexes may also be important. Female rats reach a mature body size at approximately 12 weeks of age, whereas male rats continue to grow for a much longer period and are still gaining weight (predominantly lean tissue) at 25 weeks of age. Once mature body mass has been achieved, nutrient partitioning is altered, allowing the accumulation of body fat that may, via lipotoxic effects, alter insulin signalling. The earlier occurrence of this metabolic change in the females may be the reason for the apparent differences between male and female offspring.

Table 6. Relative gene expression in the liver of 25-week-old female offspring in relation to maternal diet during pregnancy

\begin{tabular}{|c|c|c|c|c|c|c|c|c|c|c|c|}
\hline \multirow[t]{2}{*}{ Diet... } & \multicolumn{2}{|c|}{$18 \mathrm{C}(n 7)$} & \multicolumn{2}{|c|}{$18 \mathrm{~S}(n 4)$} & \multicolumn{2}{|c|}{$9 \mathrm{C}(n 6)$} & \multicolumn{2}{|c|}{$9 S(n 7)$} & \multicolumn{3}{|c|}{ Two-way ANOVA $P$ value } \\
\hline & Mean & SE & Mean & SE & Mean & SE & Mean & SE & Protein & Oil & Interaction \\
\hline Acetyl-CoA carboxylase-1 & $32 \cdot 9$ & 1.9 & $24 \cdot 6$ & 3.4 & $30 \cdot 0$ & $3 \cdot 7$ & 41.4 & 3.0 & 0.050 & 0.226 & 0.004 \\
\hline Carnitine palmitoyl transferase- 1 & 33.5 & $2 \cdot 2$ & 33.5 & $2 \cdot 2$ & $39 \cdot 1$ & $5 \cdot 3$ & $51 \cdot 2$ & $5 \cdot 7$ & 0.015 & $0 \cdot 159$ & $0 \cdot 210$ \\
\hline
\end{tabular}

The relative expression (arbitrary units) of acetyl-CoA carboxylase-1 and carnitine palmitoyl transferase-1 mRNAs expressed as the ratio of the threshold cycle value for each cDNA normalised with respect to the $18 \mathrm{~S}$ ribosomal subunit.

18C, $18 \%$ protein-corn oil; $18 \mathrm{~S}, 18 \%$ protein-soya oil; $9 \mathrm{C}, 9 \%$ protein-corn oil; $9 \mathrm{~S}, 9 \%$ protein-soya oil. 
It is important to note that, in the present study, the proteinrestricted diets were fed only during the gestational period. A restricted protein intake during lactation causes changes in milk yield and composition that lead to significant growth restriction during the neonatal period (Desai et al. 1996). The fatty acid composition of the diet also affects milk composition and production, with an increased maternal intake of $n-3$ PUFA decreasing growth rate and serum leptin levels in the suckling pups (Korotkova et al. 2002). In the present study, the animals were returned to the stock diet with an adequate protein content immediately after parturition and throughout lactation. Although feeding a low-protein diet before lactation does not inhibit subsequent performance when an adequate supply of dietary protein is provided after birth (Pine et al. 1994), there may have been an ongoing effect of the prenatal fatty acid composition. This is, however, also unlikely as studies suggest that the linoleic and arachidonic acid levels in the milk reflect the fatty acid composition of the dam's diet (Lien et al. 1994).

The magnitude of the change in glucose-stimulated insulin release was greater in our previous experiment and affected both male and female offspring (Rees et al. 2006b). The area under the curve for insulin changed approximately 3 -fold in the male and 2-fold in the female offspring, as opposed to approximately $1 \cdot 3$-fold in this experiment. This may be attributable to the different maternal dietary carbohydrate component between these two studies. The current study used a diet containing sucrose, whereas the previous study used a diet containing dextrose (glucose; Rees et al. $2006 b$ ). In rats fed diets deficient in essential fatty acids, the effect was less severe in animals fed glucose compared with sucrose, because the delta-6-desaturase and delta-5-desaturase activities were higher in animals fed glucose (Cardot et al. 1987). This also suggests that dietary carbohydrates can modulate PUFA metabolism, ultimately leading to changes in development of the insulin axis. Diets with different glycaemic indices also influence glucose metabolism and insulin action (Pawlak et al. 2004), and again this may influence fetal development.

As well as the glucose tolerance test, the interactions between PUFA and protein in the maternal diet also influenced the levels of mRNA for ACC-1 in the livers of the female offspring. The protein products of these two mRNAs are key regulators of hepatic fat synthesis and oxidation, respectively. The mRNA for ACC-1 is suppressed by fasting and then increases again within $4 \mathrm{~h}$ of a meal (Katsurada et al. 1990; Iritani et al. 1998). By evaluating the expression in the animals fasted overnight and then given a standard glucose challenge, the relative mRNA level can be compared in animals under similar nutritional states. There appears to be a greater effect of protein in the maternal diet on the levels of ACC-1 mRNAs in the liver, with an additional interaction with PUFA composition. Previous studies have shown a similar result in that the mRNA for ACC-1 increased in the livers of the offspring of dams fed low-protein diets prepared with soya oil (Maloney et al. 2003). Either maternal effects have directly altered the expression of ACC-1 in the offspring or there has been a change in the sensitivity to insulin. The two-way factorial design of this experiment shows an oil by protein interaction term, which highlights the importance of the oil in differentially regulating the transcriptional response of ACC-1 to protein in the maternal diet.

The mRNA for L-CPT-1 is counter-regulated by insulin, and there are reports that it is either unchanged or suppressed by fetal growth restriction (Lane et al. 2001; Maloney et al. 2003). The expression of L-CPT-1 is regulated by several factors. The changes in expression that result from protein restriction in utero suggest that it is also subject to longterm regulation by events occurring during development. This would infer that this is not a change in insulin regulation in the liver but rather because other regulatory factors, for example peroxisome proliferator-activated receptors or sterol regulatory element binding proteins, are being programmed during development (Lillycrop et al. 2005). As the expression of these factors changes with the age of the animals, there may be corresponding changes in the phenotype (Ehruma et al. 2006).

The present study has shown that there are interactions between macronutrients in the maternal diet and suggests that the changes in the metabolism of fatty acids may be a more widespread feature of metabolic programming involving the restricted intake of other nutrients during gestation. The complex interactions between dietary components and their impact on the maternal-fetal relationship highlight the central role of PUFA. The increasing use of vegetable oils, including corn oil, and soyabeans has markedly changed the PUFA composition of human diets in the past 100 years (Simopoulos, 1999). An increased consumption of $n$-3 PUFA coupled with a reduced intake of saturated fat has been suggested to reduce the risk of conversion from impaired glucose tolerance to type 2 diabetes in overweight persons (Nettleton \& Katz, 2005). The results of the present study suggest that this strategy may also have implications that need to be considered in the context of fetal development and the developmental origins of disease.

\section{Acknowledgements}

This work was supported by European Union Fifth Framework programme NUTRIX (QLK1-2000-00 083) and the Scottish Executive, Environment and Rural Affairs Department as part of the Rowett Research Institute core funding. We express our thanks to V. Buchan, K. Simpson, D. Wallace and colleagues for their skilled technical assistance. We also express our thanks to Dr G. Holtrop (Biomathematics and Statistics, Scotland) for advice on the statistical analysis.

\section{References}

Bonnevie-Nielsen V (1980) Experimental diets affect pancreatic insulin and glucagon differently in male and female mice. Metabolism 29, 386-391.

Burdge GC, Dunn RL, Wootton SA \& Jackson AA (2002) Effect of reduced dietary protein intake on hepatic and plasma essential fatty acid concentrations in the adult female rat: effect of pregnancy and consequences for accumulation of arachidonic and docosahexaenoic acids in fetal liver and brain. Br J Nutr 88, 379-387.

Cardot P, Chambaz J, Thomas G, Rayssiguier Y \& Bereziat G (1987) Essential fatty acid deficiency during pregnancy in the rat: influence of dietary carbohydrates. J Nutr 117, 1504-1513. 
Christie WW (1990) Preparation of methyl esters. 1. Lipid Technol 2 , $48-49$.

D'Alessandro ME, Lombardo YB \& Chicco A (2002) Effect of dietary fish oil on insulin sensitivity and metabolic fate of glucose in the skeletal muscle of normal rats. Ann Nutr Metab 46, 114-120.

Desai M, Crowther NJ, Lucas A \& Hales CN (1996) Organ-selective growth in the offspring of protein-restricted mothers. Br J Nutr 76, 591-603.

Erhuma AM, Langley-Evans SC \& Bennett AJ (In the Press) Exposure to a maternal low protein diet in rat pregnancy programmes metabolic syndrome-like phenotype in 18 month old offspring. Proc Nutr Soc.

Ghafoorunissa, Ibrahim A \& Natarajan S (2005) Substituting dietary linoleic acid with [alpha]-linolenic acid improves insulin sensitivity in sucrose fed rats. Biochim Biophys Acta Mol Cell Biol Lipids 1733, 67-75.

Iritani N, Hosomi H, Fukuda H \& Ikeda H (1995) Polyunsaturated fatty acid regulation of lipogenic enzyme gene expression in liver of genetically obese rat. Biochim Biophys Acta 1255, 1-8.

Iritani N, Komiya M, Fukuda H \& Sugimoto T (1998) Lipogenic enzyme gene expression is quickly suppressed in rats by a small amount of exogenous polyunsaturated fatty acids. J Nutr 128, 967-972.

Katsurada A, Iritani N, Fukuda H, Matsumura Y, Nishimoto N, Noguchi T \& Tanaka T (1990) Effects of nutrients and hormones on transcriptional and post-transcriptional regulation of fatty acid synthase in rat liver. Eur J Biochem 190, 427-433.

Korotkova M, Gabrielsson BG, Holmang A, Larsson BM, Hanson LA \& Strandvik B (2005) Gender-related long-term effects in adult rats by perinatal dietary ratio of n-6/n-3 fatty acids. Am J Physiol Regul Integr Comp Physiol 288, R575-R579.

Korotkova M, Gabrielsson B, Lonn M, Hanson LA \& Strandvik B (2002) Leptin levels in rat offspring are modified by the ratio of linoleic to \{alpha\}-linolenic acid in the maternal diet. $J$ Lipid Res 43, 1743-1749.

Korotkova M, Telemo E, Yamashiro Y, Hanson LA \& Strandvik B (2004) The ratio of n-6 to n-3 fatty acids in maternal diet influences the induction of neonatal immunological tolerance to ovalbumin. Clin Exp Immunol 137, 237-244.

Lane RH, Kelley DE, Gruetzmacher EM \& Devaskar SU (2001) Uteroplacental insufficiency alters hepatic fatty acid-metabolizing enzymes in juvenile and adult rats. Am J Physiol Regul Integr Comp Physiol 280, R183-R190.

Langley-Evans SC, Clamp AG, Grimble RF \& Jackson AA (1996) Influence of dietary fats upon systolic blood pressure in the rat. Int $J$ Food Sci Nutr 47, 417-425.

Lien EL, Boyle FG, Yuhas RJ \& Kuhlman CF (1994) Effect of maternal dietary arachidonic or linoleic acid on rat pup fatty acid profiles. Lipids 29, 53-59.

Lillycrop KA, Phillips ES, Jackson AA, Hanson MA \& Burdge GC (2005) Dietary protein restriction of pregnant rats induces and folic acid supplementation prevents epigenetic modification of hepatic gene expression in the offspring. $J$ Nutr 135, $1382-1386$.

McMullen S \& Langley-Evans SC (2005) Maternal low-protein diet in rat pregnancy programs blood pressure through sex-specific mechanisms. Am J Physiol Regul Integr Comp Physiol 288, R85-R90.
Maloney CA, Gosby AK, Phuyal JL, Denyer GS, Bryson JM \& Caterson ID (2003) Site-specific changes in the expression of fat-partitioning genes in weanling rats exposed to a low-protein diet in utero. Obes Res 11, 461-468.

Maloney CA, Lilley C, Cruickshank M, McKinnon C, Hay SM \& Rees WD (2005) The expression of growth-arrest genes in the liver and kidney of the protein-restricted rat fetus. Br J Nutr 94, 12-18.

Marin MC, De Tomas ME, Serres C \& Mercuri O (1995) Proteinenergy malnutrition during gestation and lactation in rats affects growth rate, brain development and essential fatty acid metabolism. J Nutr 125, 1017-1024.

Nettleton JA \& Katz R (2005) n-3 long-chain polyunsaturated fatty acids in type 2 diabetes: a review. $J$ Am Diet Assoc 105, 428-440.

Pawlak DB, Kushner JA \& Ludwig DS (2004) Effects of dietary glycaemic index on adiposity, glucose homoeostasis, and plasma lipids in animals. Lancet 364, 778-785.

Pine AP, Jessop NS \& Oldham JD (1994) Maternal protein reserves and their influence on lactational performance in rats. $\mathrm{Br} J \mathrm{Nutr}$ 71, 13-27.

Plagemann A (2005) Perinatal programming and functional teratogenesis: impact on body weight regulation and obesity. Physiol Behav 86, 661-668.

Ramanadham S, Song H, Bao S, Hsu FF, Zhang S, Ma Z, Jin C \& Turk J (2004) Islet complex lipids: involvement in the actions of group VIA calcium-independent phospholipase A(2) in beta-cells. Diabetes 53, Suppl. 1, S179-S185.

Rees WD, Hay SM, Buchan V, Antipatis C \& Palmer RM (1999) The effects of maternal protein restriction on the growth of the rat fetus and its amino acid supply. Br J Nutr 81, 243-250.

Rees WD, Hay SM \& Cruickshank M (2006a) An imbalance in the methionine content of the maternal diet reduces postnatal growth in the rat. Metabolism 55, 763-770.

Rees WD, Hay SM, Cruickshank M, Reusens B, Remacle C, Antipatis C \& Grant G (2006b) Maternal protein intake in the pregnant rat programs the insulin axis and body composition in the offspring. Metabolism 55, 642-649.

Siemelink M, Verhoef A, Dormans JA, Span PN \& Piersma AH (2002) Dietary fatty acid composition during pregnancy and lactation in the rat programs growth and glucose metabolism in the offspring. Diabetologia 45, 1397-1403.

Simopoulos AP (1999) Essential fatty acids in health and chronic disease. Am J Clin Nutr 70, 560S-569S.

Storlien LH, Kriketos AD, Calvert GD, Baur LA \& Jenkins AB (1997) Fatty acids, triglycerides and syndromes of insulin resistance. Prostaglandins Leukot Essent Fatty Acids 57, $379-385$.

Uauy R, Mena P \& Rojas C (2000) Essential fatty acids in early life: structural and functional role. Proc Nutr Soc 59, 3-15.

Zambrano E, Bautista CJ, Deas M, Martinez-Samayoa PM, GonzalezZamorano M, Ledesma H, Morales J, Larrea F \& Nathanielsz PW (2006) A low maternal protein diet during pregnancy and lactation has sex- and window of exposure-specific effects on offspring growth and food intake, glucose metabolism and serum leptin in the rat. $J$ Physiol 571, 221-230.

Zhang J, Wang C, Terroni PL, Cagampang FR, Hanson M \& Byrne CD (2005) High-unsaturated-fat, high-protein, and low-carbohydrate diet during pregnancy and lactation modulates hepatic lipid metabolism in female adult offspring. Am J Physiol Regul Integr Comp Physiol 288, R112-R118. 